\title{
Renal cell carcinoma seeding of a percutaneous biopsy tract
}

\author{
Jeffrey K. Mullins, MD; Ronald Rodriguez, $M D, P h D$
}

James Buchanan Brady Urological Institute, Johns Hopkins Medical Institutions, Baltimore, MD

Cite as: Can Urol Assoc J 2013;7:E176-E179. http://dx.doi.org/10.5489/cuaj.499

\section{Abstract}

We report the case of a 68-year-old male with extension of papillary renal cell carcinoma (Fuhrman grade III) along a percutanous biopsy tract detected at the time of partial nephrectomy. Biopsy was performed to a obtain tissue diagnosis of a complex renal cyst as the patient was unable to receive intravenous contrast for imaging due to a severe allergy. Although biopsy of indeterminate renal lesions can provide valuable diagnostic information, there are inherent risks associated with this procedure. The rare occurrence of tumour seeding should be considered when recommending percutaneous biopsy to a patient with a renal mass.

\section{Introduction}

An estimated 60920 new cases of renal cell carcinoma (RCC) will be diagnosed in the United States in 2011. ${ }^{1}$ With the increased use of cross-sectional imaging, many of these masses are diagnosed at an early stage in asymptomatic patients. ${ }^{2}$ This "stage migration" has led to increased use of active surveillance to manage small renal masses. It has recently been suggested that percutaneous biopsy plays a key role in the management algorithm for these patients. ${ }^{3,4}$ Although generally safe, percutaneous biopsy has not experienced widespread acceptance in part due to conflicting reports regarding its diagnostic accuracy..$^{5-7}$ We report a rare complication occurring after percutaneous biopsy of a renal mass that should be considered before proceeding with diagnostic renal mass biopsy.

\section{Case report}

A 68-year-old male was referred to our urology clinic after incidental discovery of a left renal cyst. The renal abnormality was first documented on imaging obtained during follow-up of an asymptomatic right common iliac artery aneurysm. Computed tomography (CT) scan with intrave-

nous contrast demonstrated a $4.2-\mathrm{cm}$ left renal cyst with mural calcifications consistent with a Bosniak class IIF cyst. Subsequent magnetic resonance imaging (MRI) confirmed the diagnosis. Unfortunately, the patient suffered a severe allergic reaction to iodinated in the past precluding him from receiving further intravenous contrast for CT or MRI. At this time biannual surveillance of the renal lesion was recommended. Subsequent non-contrast $\mathrm{CT}$ scans obtained at 6 and 12 months after initial presentation demonstrated a stable left renal cyst with no change in size or imaging characteristics.

Eighteen months after initial presentation a non-contrast CT scan demonstrated significant changes in the renal lesion. Specifically, there was a 5-mm increase in cyst diameter as well as a significant increase in CT attenuation consistent with a recent hemorrhage. These findings were concerning for malignancy (Fig. 1). Given these worrisome findings the patient was pre-medicated with prednisone in preparation for MRI with gadolinium. However, despite these precautionary measures, the patient was still unable to receive an appropriate imaging study. Given the significant limitations to imaging the patient with intravenous contrast, the decision was made to proceed with ultrasound guided biopsy of the renal lesion.

The patient was taken to the biopsy suite and underwent successful ultrasound-guided biopsy of the renal mass. During the procedure, fine needle aspiration of the left renal cyst was performed with 4 passes of a 22-gauge Chiba needle. Additionally, 2 core biopsies were performed with a 20-gauge core biopsy device. Notably, no coaxial sheath was used during the biopsy procedure. Specimens were sent to cytopathology for analysis. Pathologic review was consistent with Fuhrman grade I papillary RCC. Given these results, the patient was taken to the operating room and underwent an uneventful open partial nephrectomy 2 months after percutaneous biopsy. Pathologic analysis by a dedicated genitourinary pathologist demonstrated a $6.5-\mathrm{cm}$ Fuhrman grade III papillary RCC invading the perirenal fat within the previous biopsy tract (Fig. 2a, Fig. 2b). Extrarenal 


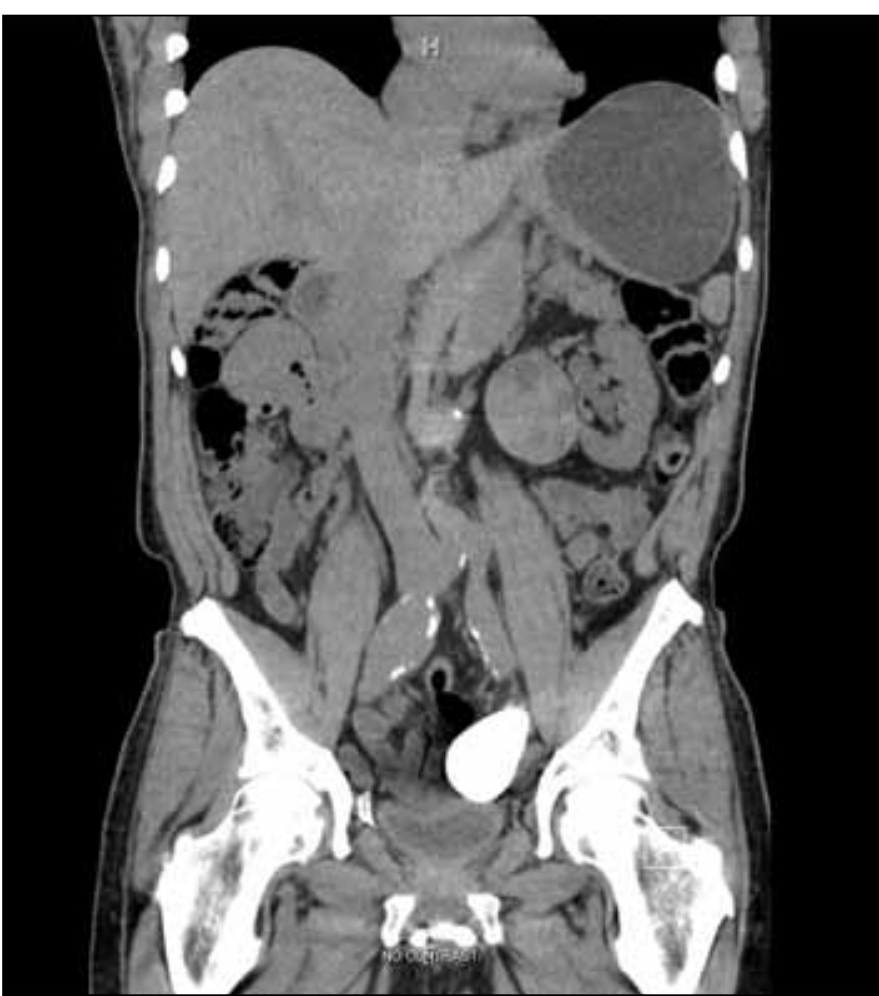

Fig. 1. Non-contrast computed tomography (CT) scan obtained 18 months after diagnosis demonstrating increased cyst diameter and increased CT attenuation concerning for malignancy.

tumour extension was isolated to the area within the biopsy tract. No perirenal extension was noted around or through the biopsy tract suggesting biopsy tract seeding as the mechanism for the extrarenal disease. All surgical margins were negative and the final pathologic stage was pT3aNxMx (as per the American Joint Committee on Cancer, 2009). The patient's postoperative course was uneventful, and he was discharged on postoperative day 5 . There has been no recurrence of his disease at the 3-month follow-up.

\section{Discussion}

RCC extension along a percutaneous biopsy tract is extremely rare with no documented cases in the past 20 years. We report a case of high-grade papillary RCC extending along a percutaneous biopsy tract detected on pathologic review of the partial nephrectomy specimen. At our institution, renal biopsy is not routinely used in the management of a renal mass suspicious for RCC. In the past year $<25$ patients have been referred for ultrasound-guided percutaneous renal mass biopsy. However, renal biopsy via a coaxial sheath is routinely performed at the time of CT-guided, percutaneous renal cryoablation. About 50 of these procedures were performed at our institution in the past year.

In the present case, renal biopsy was performed to obtain tissue diagnosis in a patient whose severe contrast allergy precluded him from receiving intravenous contrast for either CT or MRI. As has been previously reported, the biopsy specimen in the present case significantly underestimated the tumour's nuclear grade leading to a delay in the timing of partial nephrectomy. ${ }^{7}$ Fortunately, the patient's disease was completely resected and there was no evidence of recurrence with short-term follow-up. The present report should not discourage use of image-guided percutaneous biopsy of renal tumours in select cases. Rather, it should serve to raise awareness of this rare complication, and to limit its use in cases where it will not directly affect patient management.

In 1977 Gibbons and colleagues reported the first case of RCC tumour implantation 20 months after needle (18-gauge) aspiration of a renal mass. ${ }^{8}$ Since that time there have been 5 reports of implantation of RCC in percutaneous biopsy tracts. These cases occurred from 24 days to 84 months after the initial biopsy with needles ranging in size from 14 to 23-gauge. ${ }^{9-13}$ More recently, there have been several percutaneous biopsy series that have reported no cases of tumour implantation. ${ }^{714-19}$ In fact, in a review of the role of percutaneous biopsy in evaluating renal masses, Herts and Baker estimated the risk of tumour seeding at $0.01 \% .^{20}$ Of note, biopsies in these series were performed using a coaxial sheath, which has been recommended as the standard technique for renal mass biopsy. ${ }^{21}$ Although the risk of adverse oncologic outcomes after percutaneous biopsy has been minimized by modern biopsy techniques, the current report demonstrates that some risk still exists.

Although the risk of biopsy tract seeding with RCC is very low, the same cannot be said for upper tract transitional cell carcinoma (TCC). There have been multiple reports of TCC seeding after renal mass biopsy, nephrostomy tube placement for obstructive uropathy, and percutaneous management of upper tract TCC. ${ }^{9,22-24}$ It is generally considered that these tumours have a higher propensity to implant after percutaneous manipulation than RCC. This risk should be considered when deciding whether to subject a patient to percutaneous renal biopsy.

The occurrence of biopsy tract seeding has been welldocumented in several solid, non-urologic malignancies, including hepatocellular carcinoma, lung and pancreas adenocarcinoma. ${ }^{25}$ Extrapolating from the hepatocellular carcinoma literature, several technical considerations at the time of percutaneous biopsy can nearly eliminate the risk of RCC implantation. Specifically, large gauge needles, increased number of needle passes into the mass, end-cutting needles, and lack of a biopsy sheath have been implicated in tumour seeding of biopsy tracts. ${ }^{21,25,26}$ In the present case the technical risk factors were the 6 needle passes into the mass and lack of a biopsy sheath. Although multiple needle passes were necessary to obtain a histological diagnosis, the use of a sheath may have decreased the risk of tumour seeding. In a review of the techniques and outcomes percutaneous 


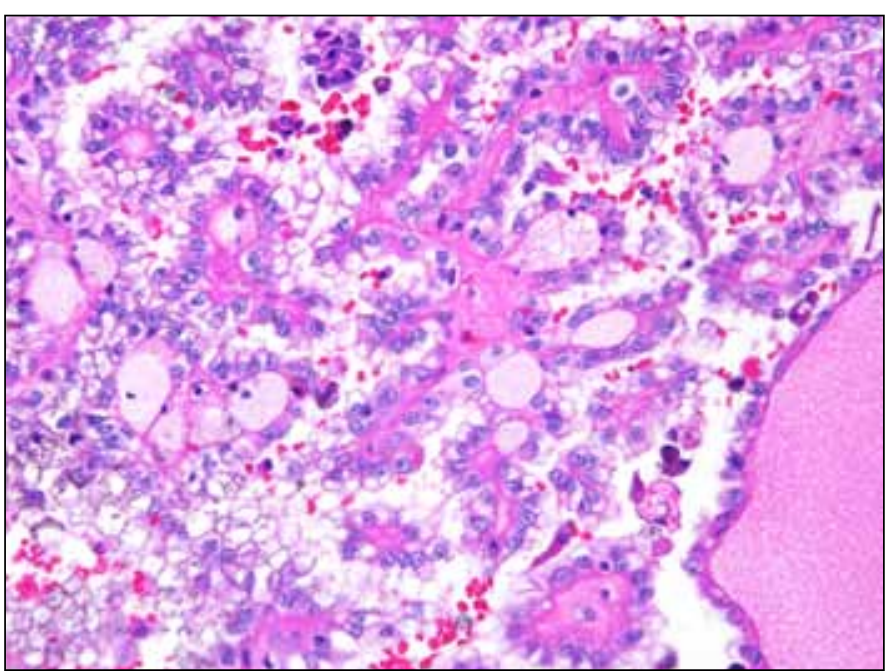

Fig. 2a. High power hematoxylin and eosin stain of partial nephrectomy consistent with Fuhrman grade III papillary renal cell carcinoma (RCC). Biopsy specimen was consistent with Fuhrman grade I papillary RCC.

biopsy of renal masses, Volpe and colleagues recommended the use of a coaxial sheath to minimize exposure of tumour cells to surrounding tissues. ${ }^{21}$ In fact, recent large biopsy series using a coaxial sheath describe no reported cases of biopsy tract seeding. ${ }^{717-19}$ The outcomes experienced by this patient highlight the potential risks and benefits associated with percutaneous biopsy of renal masses. However, technical considerations at the time of biopsy, including the use of a coaxial sheath, may nearly eliminate the risk of RCC seeding a biopsy tract.

\section{Conclusion}

We present the only contemporary report of RCC seeding a percutaneous biopsy tract. This report should not discourage the use of percutaneous biopsy of renal masses, but rather raise awareness of this exceedingly uncommon complication and the steps that can be taken to minimize the risk at the time of biopsy. Specifically, use of a coaxial biopsy sheath has nearly eliminated the risk of biopsy tract seeding after renal mass biopsy. The use of percutaneous biopsy of renal masses should be reserved for situations where obtaining a tissue diagnosis will directly impact patient care.

Competing interests: None declared.

This paper has been peer-reviewed.

\section{References}

1. Siegel R, Ward E, Brawley 0 , et al. Cancer statistics: The impact of eliminating socioeconomic and racial disparities on premature cancer deaths. CA Cancer I Clin 2011;61:212-36.

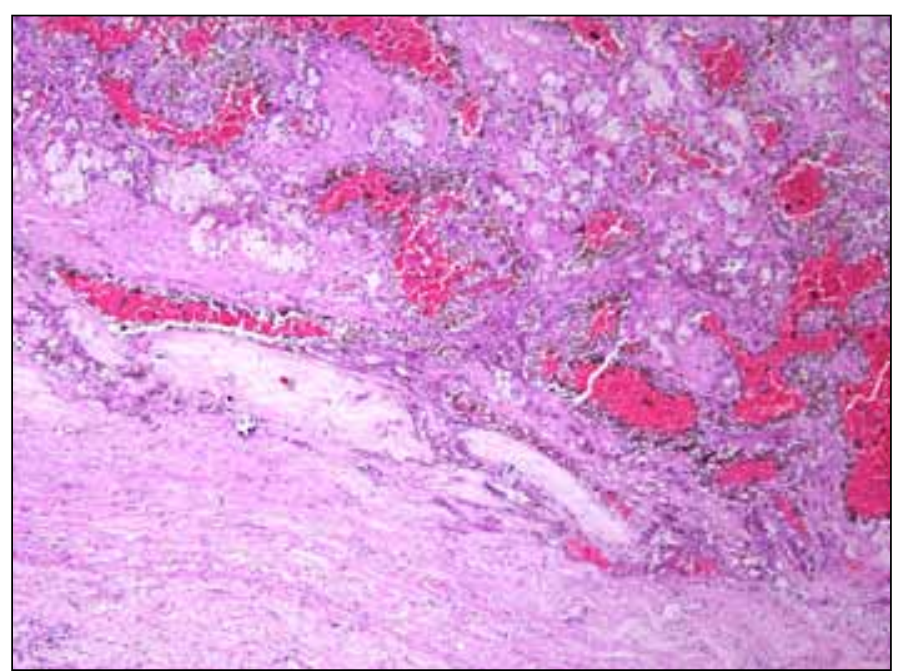

Fig. $\mathbf{2 b}$. High power view of partial nephrectomy specimen demonstrating renal cell carcinoma in a previous percutaneous biopsy tract.

2. Kane CJ, Mallin K, Ritchey J, et al. Renal cell cancer stage migration: analysis of the National Cancer Data Base. Cancer 2008;113:78-83. http://dx.doi.org/10.1002/cncr.23518

3. Phe V, Yates DR, Renard-Penna $R$, et al. Is there a contemporary role for percutaneous needle biopsy in the era of small renal masses? BJU Int 2012;109:867-72. http://dx.doi.org/10.1111/i.1464410X.2011.10544.x. Epub 2011 Sep 2.

4. Wang R, Wood DP Jr. Evolving role of renal biopsy in small renal masses. Urol Oncol 2009;27:332-4. http://dx.doi.org/10.1016/i.urolonc.2008.12.011

5. Dechet $\mathrm{CB}$, Zincke H, Sebo TJ, et al. Prospective analysis of computerized tomography and needle biopsy with permanent sectioning to determine the nature of solid renal masses in adults. J Urol 2003;169:71-4. http://dx.doi.org/10.1016/S0022-5347(05)64038-4

6. Wang R, Wolf JS Jr, Wood DP Jr, et al. Accuracy of percutaneous core biopsy in management of small renal masses. Urology 2009;73:586-90; discussion 590-1.

7. Blumenfeld AJ, Guru K, Fuchs GJ, et al. Percutaneous biopsy of renal cell carcinoma underestimates nuclear grade. Urology 2009;76:610-3. http://dx.doi.org/10.1016/j.urology.2009.09.095

8. Gibbons RP, Bush WH, Jr., Burnett LL. Needle tract seeding following aspiration of renal cell carcinoma. J Urol 1977;118(5):865-7.

9. Kiser GC, Totonchy M, Barry JM. Needle tract seeding after percutaneous renal adenocarcinoma aspiration. J Urol 1986;136:1292-3.

10. Shenoy PD, Lakhkar BN, Ghosh MK, et al. Cutaneous seeding of renal carcinoma by Chiba needle aspiration biopsy. Case report. Acta Radiol 1991;32:50-2. http://dx.doi.org/10.3109/02841859109177507

11. Wehle MJ, Grabstald H. Contraindications to needle aspiration of a solid renal mass: tumor dissemination by renal needle aspiration. J Urol 1986;136:446-8.

12. Abe M, Saitoh M. Selective renal tumour biopsy under ultrasonic guidance. Br I Urol 1992;70:7-11. http://dx.doi.org/10.1111/i.1464-410X.1992.tb15654.x

13. Auvert J, Abbou CC, Lavarenne V. Needle tract seeding following puncture of renal oncocytoma. Prog Clin Biol Res 1982:100:597-8.

14. Wood BJ, Khan MA, McGovern F, et al. Imaging guided biopsy of renal masses: indications, accuracy and impact on clinical management. J Urol 1999;161:1470-4. http://dx.doi.org/10.1016/S00225347(05)68929-X

15. Neuzillet $Y$, Lechevallier $E$, Andre $M$, et al. Accuracy and clinical role of fine needle percutaneous biopsy with computerized tomography guidance of small (less than $4.0 \mathrm{~cm}$ ) renal masses. J Urol 2004;171:1802-5. htrp://dx.doi.org/10.1097/01.ju.0000120147.51090.2b

16. Brierly RD, Thomas PJ, Harrison NW, et al. Evaluation of fine-needle aspiration cytology for renal masses. BJU Int 2000;85:14-8. http://dx.doi.org/10.1046/i.1464-410x.2000.00417.x

17. Leveridge MJ, Finelli A, Kachura JR, et al. Outcomes of small renal mass needle core biopsy, nondiagnostic percutaneous biopsy, and the role of repeat biopsy. Eur Urol 201 1;60:578-84. http://dx.doi. org/10.1016/i.eururo.2011.06.021

18. Veltri A, Garetto I, Tosetti I, et al. Diagnostic accuracy and clinical impact of imaging-guided needle biopsy of renal masses. Retrospective analysis on 150 cases. Eur Radiol 2011;21:393-401. http://dx.doi. $\operatorname{org} / 10.1007 /$ s00330-010-1938-9 
19. Volpe A, Mattar K, Finelli A, et al. Contemporary results of percutaneous biopsy of 100 small renal masses: a single center experience. J Urol 2008;180:2333-7. http://dx.doi.org/10.1016/i.juro.2008.08.014

20. Herts BR, Baker ME. The current role of percutaneous biopsy in the evaluation of renal masses. Semin Urol Oncol 1995; 13:254-61.

21. Volpe A, Kachura JR, Geddie WR, et al. Techniques, safety and accuracy of sampling of renal tumors by fine needle aspiration and core biopsy. J Urol 2007;178:379-86. http://dx.doi.org/10.1016/i. juro.2007.03.131

22. Wang SS, Ho HC, Su CK, et al. Seeding of malignant renal tumor through a nephrostomy tract. J Chin Med Assoc 2004;67:308-10.

23. Slywotzky C, Maya M. Needle tract seeding of transitional cell carcinoma following fine-needle aspiration of a renal mass. Abdom Imaging 1994;19:174-6. http://dx.doi.org/10.1007/BF00203498
24. Huang A, Low RK, deVere White R. Nephrostomy tract tumor seeding following percutaneous manipulation of a ureteral carcinoma. J Urol 1995;153(3 Pt 2):1041-2. http://dx.doi.org/10.1016/S0022$5347(01) 67632-8$

25. Robertson EG, Baxter G. Tumour seeding following percutaneous needle biopsy: The real story! Clin Radiol 2011;66:1007-14. http://dx.doi.org/10.1016/i.crad.2011.05.012. Epub 2011 Jul 23.

26. Chang S, Kim SH, Lim HK, et al. Needle tract implantation after percutaneous interventional procedures in hepatocellular carcinomas: lessons learned from a 10-year experience. Korean J Radiol 2008;9:268-74. http://dx.doi.org/10.3348/kir.2008.9.3.268

Correspondence: Dr. Jeffrey K. Mullins, 600 N. Wolfe St., Marburg 134, Baltimore, MD 21287; fax: 410-502-7711; jmulli12@Jhmi.edu 